\title{
Differentiation of relapsing-remitting and secondary progressive multiple sclerosis: a magnetic resonance spectroscopy study based on machine learning
}

Diferenciação de esclerose múltipla recorrente-remitente e progressiva secundária: um estudo de ressonância magnética com espectroscopia baseado em aprendizado de máquina

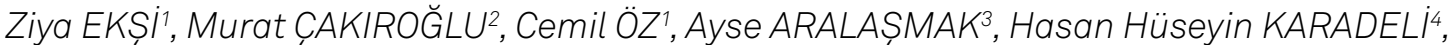
Muhammed Emin ÖZCAN ${ }^{5}$

\begin{abstract}
Introduction: Magnetic resonance imaging (MRI) is the most important tool for diagnosis and follow-up in multiple sclerosis (MS). The discrimination of relapsing-remitting MS (RRMS) from secondary progressive MS (SPMS) is clinically difficult, and developing the proposal presented in this study would contribute to the process. Objective: This study aimed to ensure the automatic classification of healthy controls, RRMS, and SPMS by using MR spectroscopy and machine learning methods. Methods: MR spectroscopy (MRS) was performed on a total of 91 participants, distributed into healthy controls ( $n=30)$, RRMS ( $n=36)$, and SPMS $(n=25)$. Firstly, MRS metabolites were identified using signal processing techniques. Secondly, feature extraction was performed based on MRS Spectra. N-acetylaspartate (NAA) was the most significant metabolite in differentiating MS types. Lastly, binary classifications (healthy controls-RRMS and RRMS-SPMS) were carried out according to features obtained by the Support Vector Machine algorithm. Results: RRMS cases were differentiated from healthy controls with 85\% accuracy, 90.91\% sensitivity, and $77.78 \%$ specificity. RRMS and SPMS were classified with $83.33 \%$ accuracy, $81.81 \%$ sensitivity, and $85.71 \%$ specificity. Conclusions: A combined analysis of MRS and computer-aided diagnosis may be useful as a complementary imaging technique to determine MS types.
\end{abstract}

Keywords: Multiple Sclerosis; Multiple Sclerosis, Relapsing-Remitting; Multiple Sclerosis, Chronic Progressive; Magnetic Resonance Spectroscopy; Machine Learning.

\section{RESUMO}

Introdução: A ressonância magnética é a ferramenta mais importante para o diagnóstico e acompanhamento na EM. A transição da EM recorrente-remitente (EMRR) para a EM progressiva secundária (EMPS) é clinicamente difícil e seria importante desenvolver a proposta apresentada neste estudo a fim de contribuir com o processo. Objetivo: o objetivo deste estudo foi garantir a classificação automática de grupo controle saudável, EMRR e EMPS usando a RM com espectroscopia e métodos de aprendizado de máquina. Métodos: Os exames de RM com espectroscopia foram realizados em um total de 91 amostras com grupo controle saudável $(n=30)$, EMRR ( $n=36)$ e EMPS ( $n=25)$. Em primeiro lugar, os metabólitos da RM com espectroscopia foram identificados usando técnicas de processamento de sinal. Em segundo lugar, a extração de recursos foi realizada a partir do MRS Spectra. O NAA foi determinado como o metabólito mais significativo na diferenciação dos tipos de MS. Por fim, as classificações binárias (Healthy Control Group-RRMS e RRMS-SPMS) foram realizadas de acordo com as características obtidas por meio do algoritmo Support Vector Machine. Resultados: Os casos de EMRR e do grupo de controle saudável foram diferenciados entre si com 85\% de acerto, 90,91\% de sensibilidade e 77,78\% de especificidade, respectivamente. A EMRR e a EMPS foram classificadas com 83,33\% de acurácia, 81,81\% de sensibilidade e 85,71\% de especificidade, respectivamente. Conclusões: Uma análise combinada de RM com espectroscopia e abordagem de diagnóstico auxiliado por computador pode ser útil como uma técnica de imagem complementar na determinação dos tipos de EM.

Palavras-chave: Esclerose Múltipla; Esclerose Múltipla Recidivante-Remitente; Esclerose Múltipla Crônica Progressiva; Ressonância Magnética com espectroscopia; Aprendizado de Máquina.

\footnotetext{
'Sakarya University, Department of Computer Engineering, Sakarya, Turkey; ${ }^{2}$ Sakarya University, Department of Mechatronic Engineering, Sakarya, Turkey;

${ }^{3}$ Memorial Bahçelievler Hospital, Department of Radiology, Istanbul, Turkey;

${ }^{4}$ Istanbul Medeniyet University, Department of Neurology, Istanbul, Turkey;

${ }^{5}$ Istanbul Yeni Yüzyıl University, Department of Neurology, Istanbul, Turkey.

Ziya EKȘi (D) https://orcid.org/0000-0001-8670-0873; Murat C̦AKIROĞLU (D) https://orcid.org/0000-0002-7672-5505;

Cemil ÖZ (DD https://orcid.org/0000-0001-9742-6021; Ayse ARALAȘMAK (DD https://orcid.org/0000-0001-8654-855X;

Hasan Hüseyin KARADELi (D) https://orcid.org/0000-0002-0470-8247; Muhammed Emin ÖZCAN (D) https://orcid.org/0000-0002-3220-6391 Correspondence: Muhammed Emin Özcan; E-mail:emozcan@gmail.com

Support: Sakarya University BAPK (Project No. 2015-50-02-012).

Conflict of interest: The authors have no conflicts of interest to declare

Author's contribution: Z.E.,C.Ö. and M.C. designed the algorithm and carried out the implementation. M.E.Ö. and A.A. collected and analyzed Magnetic Resonance Spectroscopy and data. M.E.Ö collected and analyzed clinical data. C.Ö. and Z.E. wrote the manuscript in consultation with M.E.Ö, A.A., H.H.K and M.C.

Received on: 01.05.2020 Received in its final form on:31.05.2020 Accepted on: 04.06.2020
} 


\section{INTRODUCTION}

Multiple sclerosis (MS) is an inflammatory autoimmune disorder of the central nervous system. In 2013, Lublin et al. reviewed MS phenotypes and classification from 1996. They described MS phenotypes as: clinically isolated syndrome (CIS), relapsing-remitting multiple sclerosis (RRMS), and progressive multiple sclerosis (PMS). RRMS is characterized as active or non-active. PMS, which can be primary progressive (PP) or secondary progressive (SP), has four possible sub-classifications considering the disability level ${ }^{1}$. Clinical symptoms and findings, cerebrospinal fluid (CSF) examinations, and magnetic resonance imaging (MRI) findings have been used to diagnose $\mathrm{MS}^{2,3}$. In particular, the widespread use of MRI has revolutionized the diagnosis and monitoring of MS.

Recent studies have emphasized that MR spectroscopy (MRS) is a convenient alternative method to analyze MS, understand its pathogenesis, and determine its course $^{4,5,6,7}$. Vingara et al. calculated metabolic changes in MRS data obtained from RRMS and healthy control groups by statistical methods and declared that MRS data would be useful in clinical trials ${ }^{8}$. Kirov et al. characterized and followed metabolic changes between the control group and early RRMS patients using MRS data . Furthermore, N-acetylaspartate (NAA) peak decreases when an orientation from RRMS to SPMS occurs during the course of the disease. NAA peaks were shortened when RRMS switched to SPMS during the MS course ${ }^{10,11}$. Pan et al. determined MRS metabolic values in RRMS, SPMS, and PPMS groups and calculated metabolic changes by statistical methods ${ }^{12}$. Narayana et al. compared metabolic values between PPMS and control groups using automatic analysis software ${ }^{13}$. Changes in NAA levels outside MS brain lesions and inside spinal plaques were studied in benign versus non-benign MS, and the values obtained were compared with healthy controls ${ }^{14,15}$. Current literature mostly has data relevant to metabolite changes in MS; however, a few studies tried to simultaneously obtain an MS-diagnosis and a quantitative disease severity-prediction with the aid of MRS. The reason for this scarcity may be the difficulty in examining and interpreting MRS signals. Therefore, artificial intelligence and computer-aided diagnosis (CAD) are novel and effective methods that can contribute to overcoming the problems mentioned above ${ }^{16,17,18}$. To the best of our knowledge, very few studies have addressed the determination of MS types with the help of combined approaches, adopting both MRS and advanced machine learning algorithms. Ion-Margineanu et al. classified CIS, RRMS, PPMS, and SPMS patients using machine learning algorithms trained on clinical data (e.g., patient age, disease duration, and Expanded Disability Status Scale - EDSS) combined with lesion loads and magnetic resonance metabolic features ${ }^{19}$.
This study examined the combination of MRS and a machine learning method for binary classification of healthy controls-RRMS and RRMS-SPMS. Moreover, we discussed the effectiveness of MRS in MS diagnosis.

\section{METHODS}

\section{Patient population and imaging}

MS data were obtained from 61 consecutive MS patients who voluntarily participated in this study, which was conducted in the MS Clinic of the Neurology Department at the Bezmialem University Hospital between June and December 2015, following the McDonald criteria $(2010)^{20}$. In addition, a healthy control group was created with demographic characteristics similar to those of the RRMS group. Two neurologists with clinical experience in MS and blinded to each other confirmed the diagnosis of healthy controls, RRMS, and SPMS. Among 61 MS patients, 36 were diagnosed with RRMS and the remainder with SPMS. The healthy control group consisted of 30 participants with a similar age to that of the RRMS group and no statistically significant difference $(\mathrm{p}=0.18)$. Four patients, who had additional neurological disorders, were excluded from the patient group (migraine, brain tumor, etc.). Table 1 presents demographic and clinical features of the study population.

MRS was performed with a $1.5 \mathrm{~T}$ Siemens Avanto ${ }^{\circledR}$ MRI scanner. MRS data were obtained from short echo time single-voxel ${ }^{1} \mathrm{H}$ spectroscopy (SE) signals in STEAM sequence, and the parameters used were: repetition time $(\mathrm{TR})=2000 \mathrm{~ms}$, echo time $(\mathrm{TE})=32 \mathrm{~ms}$, and spectral width $(\mathrm{SW})=1000 \mathrm{~Hz}$.

Anatomical images included sagittal, axial, and coronal FLAIR sequences. FLAIR MR images (9000/109/1 - TR/TE/ number of excitations [NEX]) were obtained with a $5 \mathrm{~mm}$ thick section (axial, sagittal, and coronal). Figure 1 shows a sample voxel placement for RRMS and SPMS lesions.

For an automatic specification of MS types via single-voxel spectroscopy, a CAD system was designed, consisting of four different basic steps described in Figure 2. Data acquisition, signal processing, feature extraction, and

Table 1. Demographic and clinical features of the study population.

\begin{tabular}{lccc} 
& Control group & RRMS & SPMS \\
\hline $\begin{array}{l}\text { Number of } \\
\text { subjects }\end{array}$ & 30 (w:18, m:12) & $36(\mathrm{w}: 24, \mathrm{~m}: 12)$ & 25 (w:16, m:9) \\
Age $^{*}$ & $37.3 \pm 9.87$ & $34.2 \pm 8.85$ & $48.1 \pm 8.84$ \\
$\begin{array}{l}\text { Disease } \\
\text { duration }(\mathrm{y})^{*}\end{array}$ & ---- & $2.33 \pm 2.08$ & $10.51 \pm 6.32$ \\
EDSS $^{+}$ & ---- & $1(0-3.5)$ & $4(2.5-7.5)$ \\
\hline
\end{tabular}

RRMS: relapsing-remitting multiple sclerosis; SPMS: secondary progressive multiple sclerosis; EDSS: Expanded Disability Status Scale; w: women; m: men; y: years. "Values are expressed as mean \pm standard deviation. ${ }^{+}$Values are expressed as median (min-max) values. 
classification stages comprised the different sub-processing steps. All experimental studies were performed with a laptop working on a Windows 7 operating system, 4-core $2.4 \mathrm{GHz}$ i7 processor, and 16 GB memory. The TARQUIN (Version 4.3.6) and MATLAB (Version R2010b) programs were used in all experiments.

\section{Statistical analysis}

This study used the SPSS (Version:20.0) software for all statistical data analysis. Concentrations of NAA, choline (Cho), creatine (Cr), and myo-inositol (MI) metabolites clinically collected from healthy control and MS groups and rates of these metabolites were statistically analyzed. Statistical significance was set as $\mathrm{p}<0.05$. Data were compared to a normal distribution using the Kolmogorov-Smirnov test and histograms. Normally distributed data were analyzed with

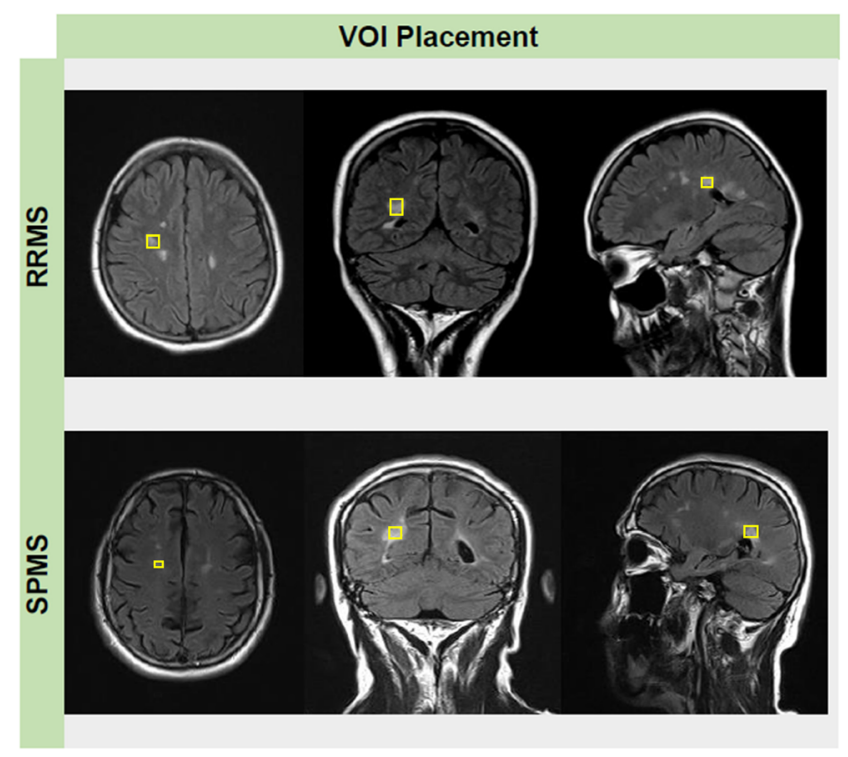

Figure 1. Sample voxel placement

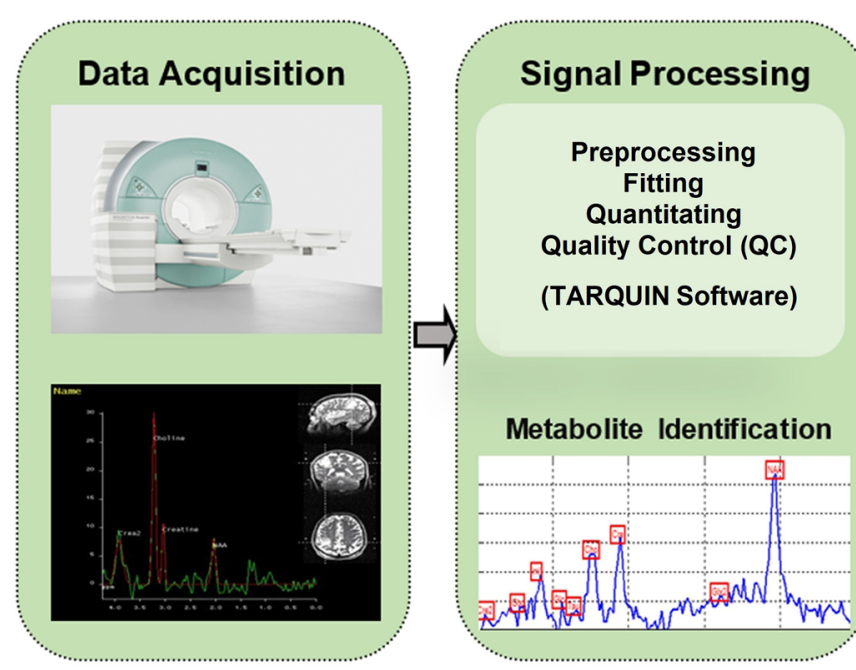

Figure 2. Process steps and algorithms of the study.
Student's $t$-test, and non-normally distributed data were assessed with the Mann-Whitney U-test. In addition, a boxplot was used to show metabolites and their rates using the OriginPro software (Version 9.3).

\section{Single-voxel spectroscopy processing}

Single-voxel spectroscopy (SVS) data were obtained from Siemens .rda files. SVS raw data were analyzed with the TARQUIN software. TARQUIN is an accurate and robust algorithm for assessing and quantifying single-voxel MRS analysis in the time domain ${ }^{21}$. TARQUIN has some pre-processing and fitting modules for quantifying MRS metabolites. Eddy current correction using Klose's method ${ }^{22}$, water removal by Hankel singular value decomposition (HSVD), phase correction, automatic referencing, basis-set simulation, signal model, and constraint fitting were applied by TARQUIN for pre-processing and quantitation of either the time or frequency domain. Time-domain signals were transformed into frequency-domain ones using Fourier transform for the actual quantification. The main metabolites of interest area ranging from 5.5 to $9.0 \mathrm{ppm}$ in this study. ${ }^{19,23,24}$.

Conventional MRI and SVS data were examined by two radiology experts with at least 10 years of experience in the field. All SVS data were reviewed for quality and assessed with quality control (QC) criteria. Following the experts' opinion, SVS spectra of insufficient quality were not included in the final data set. In addition, all SVS data reached the TARQUIN quality control values for two parameters - fullwidth half-maximum (FWHM) and signal-to-noise (SNR) ratio. The FWHM obtained from TARQUIN was $\leq 0.15 \mathrm{ppm}$. The SNR obtained from TARQUIN was $>5^{19,24}$.

MRS spectra and metabolite changes in healthy controls and RRMS and SPMS patients were identified with the help of these procedures. Figure 3 shows sample MR images and MRS spectra of healthy controls and RRMS and SPMS patients.

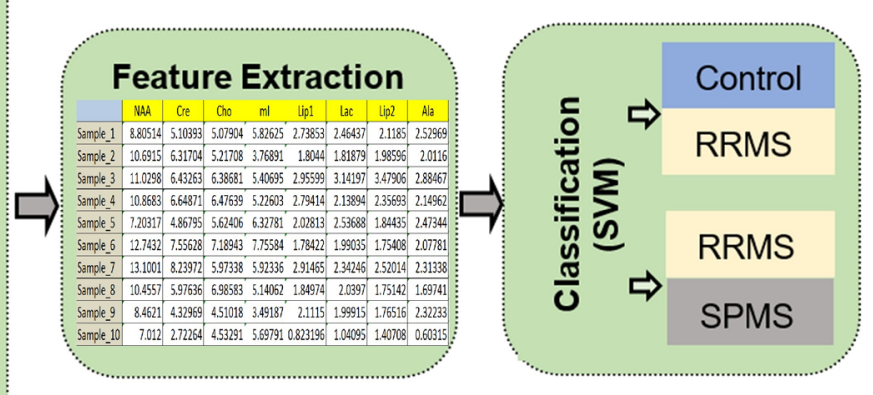




\section{Feature extraction/selection}

SVS comprises 1024 data points in the TARQUIN software. In this step, SVS data features were extracted, and the most representative ones were determined. The current study used the peak integration (PI) method of MATLAB to obtain significant features ${ }^{25}$. The PI method calculates peak values of the most important metabolites, such as NAA, $\mathrm{Cho}, \mathrm{Cr}$, and MI, and the area under these peaks for each selected metabolite resonance. Fifteen ranges were used for short TE spectra, which were integrated into a window of $0.15 \mathrm{ppm}$ around the expected chemical shift of the main resonance of the metabolites ${ }^{26}$. These values were used as classification input.

\section{Classification}

The feature vectors obtained in the feature extraction step were used to classify healthy controls-RRMS and RRMSSPMS. Feature standardization was carried out for each classification task. Four-fold cross-validation was used in the feature standardization step. In this method, feature sets of each patient were randomly divided into four parts - one used for the test and the remaining three for training. This process was repeated until each of the four folds was used as the testing set. This procedure was repeated until all feature sets from all patients were tested.
We also used a Support Vector Machine (SVM), which is frequently adopted in fields such as image processing, statistics, and machine learning. This method can classify two or more classes of linear or non-linear data. It counts with optimization techniques, which attempt to find the optimal separating plane between the two classes. The SVM algorithm classifies the features that cannot be separated linearly with kernel functions. Linear, radial basis, polynomial, and gaussian kernel functions are commonly used ${ }^{27,28}$. This study used the quadratic kernel function. Quadratic kernel function is a popular form of polynomial kernel function. Polynomial kernel functions whose "d" value is 1 receive the name of linear kernel function; when this value is 2, they are named quadratic kernel function ${ }^{29}$. Determining hyperparameters is critical to the performance of quadratic kernel functions. This study adopted grid-search and k-fold cross-validation methods to find optimal hyperparameter tuning $(\mathrm{C}, \gamma, r$, and $\mathrm{d})$. In the hyperparameter optimization process via grid-search with cross-validation, all results were observed for combinations of all values in a determined inter$\mathrm{val}$, and the best combination was chosen for the hyperparameter group. In the grid-search method, $C\left(2^{-10}, 2^{-9}, \ldots, 2^{1}\right), \gamma\left(2^{-10}, 2^{-9}\right.$, $\left.\ldots, 2^{1}\right), r\left(2^{-10}, 2^{-9}, \ldots, 2^{1}\right)$, and $d(0,1,2,3,4,5)$ intervals were chosen for hyperparameter tuning. Class imbalance is a common problem in machine learning algorithms. Thus, we set the class_ weight parameter to 'balanced' to adjust for class imbalance.
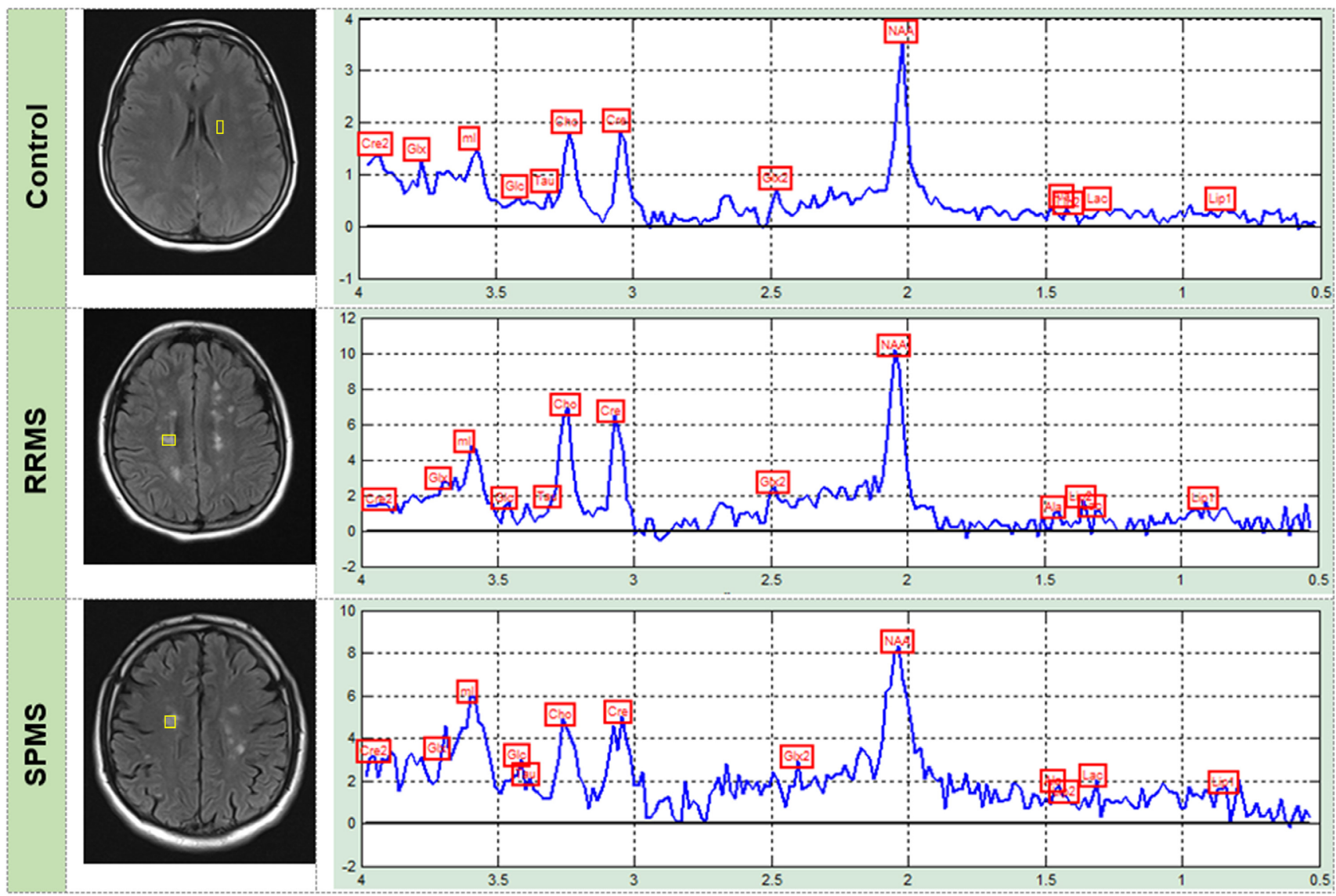

Figure 3. MR images and MRS signals of healthy controls and RRMS and SPMS patients. 


\section{RESULTS}

In this study, SVS data obtained from 30 healthy controls and 36 RRMS and 25 SPMS patients were used as datasets. First, we assessed the detectability of MS types according to metabolite changes by performing a basic statistical analysis of the dataset. Based on the analysis, the mean levels of NAA peaks were $5.93 \pm 2.92,9.24 \pm 2.01$, and $7.70 \pm 2.85$ in healthy controls, RRMS patients, and SPMS patients, respectively. These values may reflect a decreasing trend in NAA peak in progressive forms of MS. In healthy controls, the mean level of $\mathrm{Cr}$ and Cho metabolites were $2.93 \pm 1.75$ and $2.83 \pm 1.86$, respectively. The mean levels of the $\mathrm{Cr}$ and Cho metabolites were $5.88 \pm 1.41$ and $5.89 \pm 1.42$, respectively, in RRMS patients and $4.93 \pm 1.95$ and $4.93 \pm 2.11$, respectively, in SPMS patients.

Figure 4 shows a box-plot with the statistical details of the dataset used in the study. As seen in Figure 4, metabolite ranges are closer in the RRMS and SPMS groups. Therefore, differentiating MS types with the help of basic statistical methods is difficult.

Second, the performance of the proposed CAD system, which was developed to overcome the mentioned limitation in the differentiation of MS types, was evaluated according to accuracy (Acc), sensitivity (Sen), and specificity (Spe) parameters.

We used binary classification (healthy controls-RRMS and RRMS-SPMS) to differentiate MS types. In the first evaluation, healthy controls and RRMS patients were categorized in binary classification. Forty-six SVS data randomly selected from the dataset were used for training, and the remaining 20 were used for tests (70\% training, 30\% test). Table 2 presents the results obtained.

According to test results, 10 of the 11 patients diagnosed with RRMS and 7 of the 9 individuals considered healthy controls by neurologists were correctly classified by the proposed CAD system. Acc, Sen, and Spe of the CAD system were $85 \%, 90.91 \%$, and $77.78 \%$, respectively.

Furthermore, RRMS and SPMS patients were classified using the SVM method. Forty-tree MRS data were used for training, and the remaining 18 MRS data were used for testing. Table 3 reports the test results of the RRMS and SPMS classification.

According to the experiments, 9 of the 11 patients diagnosed with RRMS and 6 of the 7 patients diagnosed with SPMS by neurologists were correctly classified by the proposed CAD system. Consequently, Acc of the system was $83.33 \%$.

The second evaluation used a k-fold $(\mathrm{k}=4)$ cross-validation technique ${ }^{30}$. In this method, the SVS dataset was randomly divided into four parts - one used for the test and the remaining three for training. Tables 4 and 5 describe the binary classification results of the 4-fold cross-validation.

The total performance of RRMS and healthy control classification was: Acc: $83.33 \pm 2.9 \%$, Sen: $80.56 \pm 4.81 \%$, and Spe: $86.67 \pm 10.13 \%$.

As shown in Table 5, the 4-fold cross-validation results of RRMS and SPMS were: Acc: $81.96 \pm 4.91 \%$, Sen: $83.33 \pm 5.55 \%$, and Spe: $80 \pm 5.15 \%$.

Table 2. Assessment of the system performance success as a confusion matrix for the classification of RRMS cases and healthy controls.

\begin{tabular}{|c|c|c|c|c|}
\hline \multirow{2}{*}{$\begin{array}{l}\text { Gold } \\
\text { standard }\end{array}$} & \multicolumn{2}{|c|}{ Predicted } & \multirow{2}{*}{ Total } & \multirow{2}{*}{ Results (\%) } \\
\hline & RRMS & Control & & \\
\hline RRMS & 10 & 1 & 11 & \multirow{3}{*}{$\begin{array}{c}\text { Accuracy: } 85 \\
\text { Sensitivity: } 90.91 \\
\text { Specificity: } 77.78\end{array}$} \\
\hline Control & 2 & 7 & 9 & \\
\hline Total & 12 & 8 & 20 & \\
\hline
\end{tabular}

RRMS: relapsing-remitting multiple sclerosis.
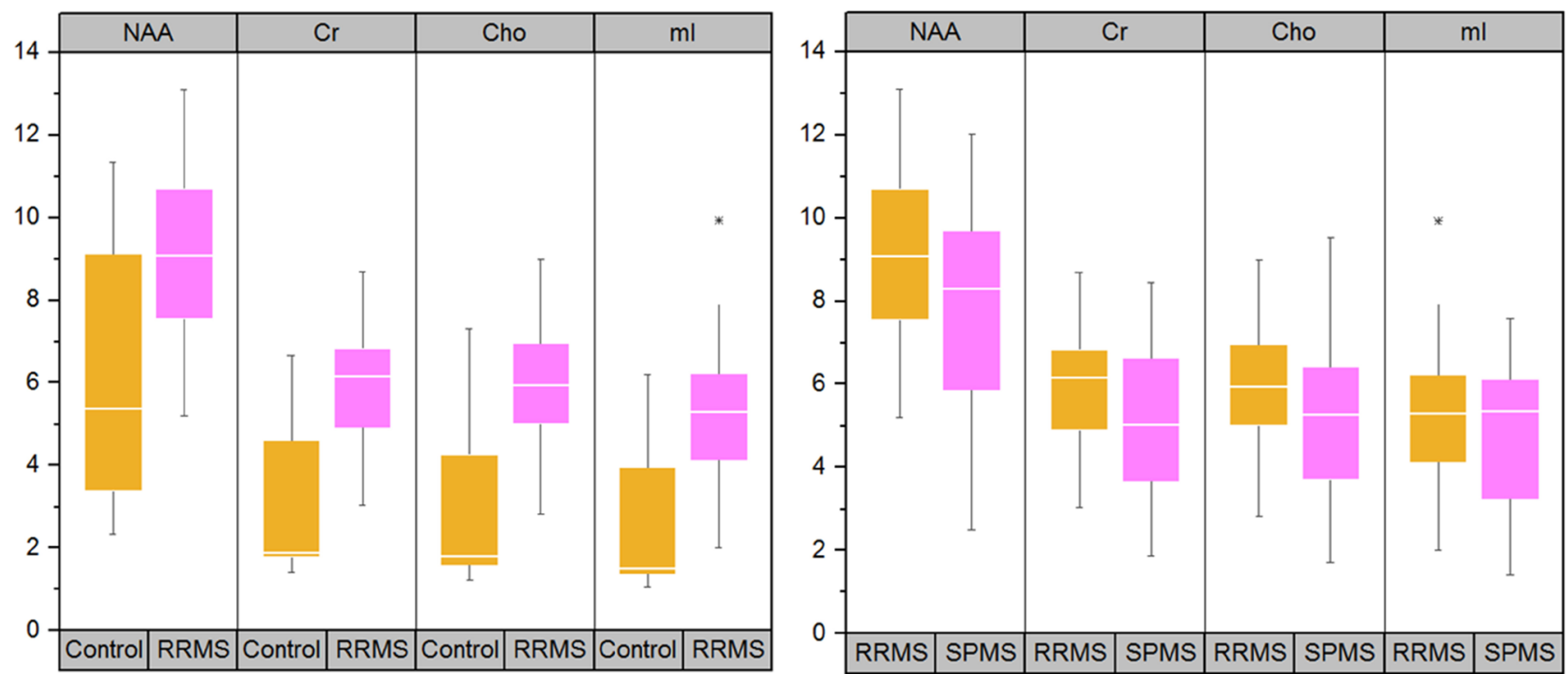

Figure 4. Box-plots of metabolite levels in healthy controls and RRMS and SPMS patients. 
Table 3. Assessment of the system performance success as a confusion matrix for the classification of RRMS and SPMS.

\begin{tabular}{|c|c|c|c|c|}
\hline \multirow{2}{*}{$\begin{array}{l}\text { Gold } \\
\text { standard }\end{array}$} & \multicolumn{2}{|c|}{ Predicted } & \multirow{2}{*}{ Total } & \multirow{2}{*}{ Results (\%) } \\
\hline & RRMS & SPMS & & \\
\hline RRMS & 9 & 2 & 11 & \multirow{3}{*}{$\begin{array}{l}\text { Accuracy: } 83.33 \\
\text { Sensitivity: } 81.81 \\
\text { Specificity: } 85.71\end{array}$} \\
\hline SPMS & 1 & 6 & 7 & \\
\hline Total & 10 & 8 & 18 & \\
\hline
\end{tabular}

RRMS: relapsing-remitting multiple sclerosis; SPMS: secondary progressive multiple sclerosis.

Table 4. Four-fold cross-validation results for the classification of RRMS cases and healthy controls.

\begin{tabular}{|c|c|c|c|c|}
\hline \multirow{2}{*}{$\begin{array}{l}\text { Gold } \\
\text { standard }\end{array}$} & \multicolumn{2}{|c|}{ Predicted } & \multirow{2}{*}{ Total } & \multirow{2}{*}{ Results (\%) } \\
\hline & RRMS & Control & & \\
\hline RRMS & 29 & 7 & 36 & \multirow{3}{*}{$\begin{array}{c}\text { Accuracy: } 83.33 \pm 2.9 \\
\text { Sensitivity: } \\
80.56 \pm 4.81 \\
\text { Specificity: } \\
86.67 \pm 10.13\end{array}$} \\
\hline Control & 4 & 26 & 30 & \\
\hline Total & 33 & 3 & 66 & \\
\hline
\end{tabular}

RRMS: relapsing-remitting multiple sclerosis.

Table 5. Four-fold cross-validation results for the classification of RRMS and SPMS

\begin{tabular}{|c|c|c|c|c|}
\hline \multirow{2}{*}{$\begin{array}{l}\text { Gold } \\
\text { standard }\end{array}$} & \multicolumn{2}{|c|}{ Predicted } & \multirow{2}{*}{ Total } & \multirow{2}{*}{ Results (\%) } \\
\hline & RRMS & SPMS & & \\
\hline RRMS & 30 & 6 & 36 & \multirow{3}{*}{$\begin{array}{c}\text { Accuracy: } 81.96 \pm 4.91 \\
\text { Sensitivity: } \\
83.33 \pm 5.55 \\
\text { Specificity: } 80 \pm 5.15\end{array}$} \\
\hline SPMS & 5 & 20 & 25 & \\
\hline Total & 35 & 26 & 61 & \\
\hline
\end{tabular}

RRMS: relapsing-remitting multiple sclerosis; SPMS: secondary progressive multiple sclerosis.

\section{DISCUSSION}

The literature has emphasized that MRS may be used as a complementary imaging technique in the follow-up and for understanding the disease mechanisms ${ }^{4,7}$. Moreover, the NAA metabolite should be taken into consideration when determining MS types. Other metabolites do not demonstrate any significant change regarding disease classification $^{5,6}$. Many studies have analyzed the changes in metabolite levels to diagnose MS. However, MRS is still not a preferred imaging technique for MS diagnosis. This failure may be related to many reasons, such as the difficulty of conventional radiologists in analyzing and interpreting MRS signals, the lack of precise imaging standardization, and the inability to achieve the intended specificity and sensitivity in clinical practice ${ }^{31}$.

$\mathrm{CAD}$ approaches based on MRS are generally recommended to detect tumors, determine tumor grades, and differentiate tumors from other brain lesions ${ }^{32,33,34,35}$. Our study examined the usability of MRS in MS and identified MS types using machine learning approaches. The literature has few studies addressing MS detection and classification based on machine learning and MRS data ${ }^{19}$. For example, Vingara et al. distinguished MRS data from RRMS and control groups with an accuracy of $86 \%$ using advanced statistics $^{8}$. In contrast to their methodology, we applied machine learning algorithms instead of statistical methods, which allowed us to differentiate between healthy controls, RRMS patients, and SPMS patients. To the best of our knowledge, our study is the first to demonstrate the possibility of automatic differentiation between healthy controls, RRMS cases, and SPMS cases with high accuracy and machine learning methods.

According to our results, we can affirm that SVS associated with machine learning approaches has the potential to contribute further to identifying MS types. Differentiating between healthy controls, RRMS cases, and SPMS cases is clinically important since the type of MS determines the treatment strategy. If the RRMS-SPMS differentiation occurs at a very early stage, the treatment algorithm can be organized accordingly ${ }^{36}$.

Corroborating other studies ${ }^{5,6}$, we also found that the most determining metabolite in distinguishing MS types is NAA. Abd El-Rahman et al. have stated that RRMS and SPMS patients can be identified with the help of MRS; however, they did not use the computer-aided machine learning method. The same study detected a significant decrease in MS plaques and NAA and Cr peaks among SPMS patients. At the same time, the Cho peak showed no significant changes ${ }^{11}$. Similarly, a study presented by Aboul-Enein reported decreases in NAA, $\mathrm{Cho}$, and $\mathrm{Cr}$ peaks in parallel with increasing disease severity ${ }^{10}$. In our study, the most significant change was observed in the NAA peak. Certain decreases were found in Cho and Cr peaks, but in contrast to the studies mentioned above, the levels of $\mathrm{NAA} / \mathrm{Cr}$ and NAA/Cho ratios showed no significant differences. Furthermore, MI peak levels decreased with the progress of the disease.

Some limitations of our study and areas for future research should be mentioned. The most important factor that determined the success of our approach is the training dataset. If the MRS dataset is enriched with healthy control, RRMS, and SPMS samples, the success of our method increases due to better learning of MS cases. Another limitation of the study was obtaining MRS data from a single MR scanner. In future studies, the proposed CAD can be evaluated with MRS data collected from different MR scanners. Moreover, a future study is planned in which RRMS, SPMS, and PPMS will be compared separately with sufficient numbers of patients in each group. Also, a new feature extraction method can be proposed for MRS data.

In conclusion, we have investigated the ability of SVS associated with a machine learning approach in differentiating between healthy controls, RRMS cases, and SPMS cases. 
We found that healthy controls-RRMS and RRMS-SPMS can be used with a moderate degree of sensitivity and specificity. In future works, novel CAD approaches combined with MRS might provide supportive means for MRI to diagnose and classify different MS types.

\section{ACKNOWLEDGMENTS}

We would like to thank all patients included in the study for approving the use of their MRS data for research and educational purposes.

\section{References}

1. Lublin FD, Reingold SC, Cohen JA, Cutter GR, Sørensen PS, Thompson AJ, et al. Defining the clinical course of multiple sclerosis: the 2013 revisions. Neurology. 2014 Jul 15;83(3):278-86. https://doi. org/10.1212/WNL.0000000000000560

2. Freedman MS, Thompson EJ, Deisenhammer F, Giovannoni G, Grimsley G, Keir G, et al. Recommended standard of cerebrospinal fluid analysis in the diagnosis of multiple sclerosis: a consensus statement. Arch Neurol. 2005 Jun;62(6):865-70. https://doi. org/10.1001/archneur.62.6.865

3. Lugue FA, Jaffe SL. Cerebrospinal fluid analysis in multiple sclerosis. Int Rev Neurobiol. 2007 Jun;79:341-56. https://doi.org/10.1016/ S0074-7742(07)79015-3

4. Sajja BR, Wolinsky JS, Narayana PA. Proton magnetic resonance spectroscopy in multiple sclerosis. Neuroimaging Clin N Am. 2009 Feb;19(1):45-58. https://doi.org/10.1016/j.nic.2008.08.002

5. Saindane AM, Cha S, Law M, Xue X, Knopp EA, Zagzag D. Proton MR spectroscopy of tumefactive demyelinating lesions. AJNR Am J Neuroradiol. 2002 Sep;23(8):1378-86

6. De Stefano N, Bartolozzi ML, Guidi L, Stromillo ML, Federico A. Magnetic resonance spectroscopy as a measure of brain damage in multiple sclerosis. J Neurol Sci. 2005 Jun 15; 233(1-2):203-8. https:// doi.org/10.1016/j.jns.2005.03.018

7. Ge Y. Multiple sclerosis: the role of MR imaging. AJNR Am J Neuroradiol. 2006 Jun-Jul;27(6):1165-76.

8. Vingara LK, Yu HJ, Wagshul ME, Serafin D, Christodoulou C, Pelczer I, et al. Metabolomic approach to human brain spectroscopy identifies associations between clinical features and the frontal lobe metabolome in multiple sclerosis. Neuroimage. 2013 Nov 15;82:58694. https://doi.org/10.1016/j.neuroimage.2013.05.125

9. Kirov II, Tal A, Babb JS, Herbert J, Gonen O. Serial proton MR spectroscopy of gray and white matter in relapsing-remitting MS. Neurology. 2013 Jan 1;80(1):39-46. https://doi.org/10.1212/ WNL.0b013e31827b1a8c

10. Aboul-Enein F.MR spectroscopy in multiple sclerosis - a new piece of the puzzle or just a new puzzle. Magnetic Resonance Spectroscopy. InTech 2012 Mar;3:47-72. https://doi.org/10.5772/32340

11. Abd El-Rahman HM, Hasan DI, Selim HA, Lotfi SM, Elsayed WM. Clinical use of $\mathrm{H}^{1} \mathrm{MR}$ spectroscopy in assessment of relapsing remitting and secondary progressive multiple sclerosis. Egypt $J$ Radiol Nucl Med. 2012 Jun;43(2)257-64. https://doi.org/10.1016/j. ejrnm.2011.12.009

12. Pan JW, Coyle PK, Bashir K, Whitaker JN, Krupp LB, Hetherington HP. Metabolic differences between multiple sclerosis subtypes measured by quantitative MR spectroscopy. Mult Scler. 2002 May;8(3):200-6. https://doi.org/10.1191/1352458502ms802oa

13. Narayana PA, Wolinsky JS, Rao SB, He R, Mehta M; PROMiSe Trial MRSI Group. Multicentre proton magnetic resonance spectroscopy imaging of primary progressive multiple sclerosis. Mult Scler. 2004 May;10(3):73-8. https://doi.org/10.1191/1352458504ms1035oa

14. Achtnichts L, Gonen O, Rigotti DJ, Babb JS, Naegelin Y, Penner IK, et al. Global N-acetylaspartate concentration in benign and non-benign multiple sclerosis patients of long disease duration. Eur J Radiol. 2013 Dec;82(12):848-52. https://doi.org/10.1016/j. ejrad.2013.08.037
15. Marliani AF, Clementi V, Albini Riccioli L, Agati R, Carpenzano M, Salvi F, et al. Quantitative cervical spinal cord 3T Proton MR spectroscopy in Multiple Sclerosis. Am J Neuroradiol. 2010 Jan;31(1):180-4. https://doi.org/10.3174/ajnr.A1738

16. Vieira BH, Dos Santos AC, Salmon CEG. Pattern recognition of abscesses and brain tumors through MR spectroscopy: Comparison of experimental conditions and radiological findings. Res Biomed Eng. 2017; 33(3):185-194.

17. Olliverre N, Yang G, Slabauhg G, Reyes-Aldasoro CC, Alonso E. Generating magnetic resonance spectroscopy imaging data of brain tumours from linear, non-linear and deep learning models. Springer, Cham. 2018 Sep;11037:130-138. https://doi.org/10.1007/978-3-03000536-8_14

18. Gurbani SS, Schreibmann E, Maudsley AA, Cordova JS, Soher BJ, Poptani $\mathrm{H}$, et al. A convolutional neural network to filter artifacts in spectroscopic MRI. Magn Reson Med. 2018 Nov;80(5):1765-1775. https://doi.org/10.1002/mrm.27166

19. Ion-Mărgineanu A, Kocevar G, Stamile C, Sima DM, Durand-Dubief F, Van Huffel S, et al. achine Learning Approach for Classifying Multiple Sclerosis Courses by Combining Clinical Data with Lesion Loads and Magnetic Resonance Metabolic Features. Front Neurosci. 2017 Jul 11;11:398. https://doi.org/10.3389/fnins.2017.00398

20. Polman CH, Reingold SC, Banwell B, Clanet M, Cohen JA, Filippi M, et al. Diagnostic criteria for multiple sclerosis: 2010 revisions to the McDonald criteria. Ann Neurol. 2011 Feb;69(2):292-302. https://doi. org/10.1002/ana.22366

21. Wilson M, Reynolds G, Kauppinen RA, Arvanitis TN, Peet AC. A constrained least-squares approach to the automated quantitation of in vivo ${ }^{1} \mathrm{H}$ magnetic resonance spectroscopy data. Magn Reson Med. 2011 Jan;65(1):1-12. https://doi.org/10.1002/mrm.22579

22. Klose U. In vivo proton spectroscopy in presence of eddy currents. Magn Reson Med. 1990 Apr;14(1):26-30. https://doi.org/10.1002/ mrm.1910140104

23. Zarinabad N, Abernethy LJ, Avula S, Davies NP, Rodriguez Gutierrez $\mathrm{D}$, Jaspan T, et al. Application of pattern recognition techniques for classification of pediatric brain tumors by in vivo $3 T^{1} \mathrm{H}-\mathrm{MR}$ spectroscopy-A multi-center study. Magn Reson Med. 2018 Apr;79(4):2359-66. https://doi.org/10.1002/mrm.26837

24. Gill SK. Isingle voxel proton magnetic resonance spectroscopy of childhood brain tumours [internet]. Birmingham: University Of Birmingham; 2013. 256p. [Acesso em: 02 nov. 2020]. Disponível em: https://etheses.bham.ac.uk//id/eprint/4899/1/Gill14PhD.pdf.

25. Fuster-Garcia E, Navarro C, Vicente J, Tortajada S, García-Gómez JM, Sáez C, et al. Compatibility between 3T 1H SV-MRS data and automatic brain tumour diagnosis support systems based on databases of 1.5T 1H SV-MRS spectra. MAGMA. 2011 Feb;24(1):3542. https://doi.org/10.1007/s10334-010-0241-8

26. García-Gómez JM. Brain tumor classification using magnetic resonance spectroscopy. In: Hayat M. (eds) Tumors of the central nervous system. 2011 May;3:5-19. https://doi.org/10.1007/978-94007-1399-4_2

27. Burges CJC. A tutorial on support vector machines for pattern recognition. Data Min Knowl Discov. 1998;2:121-67. https://doi. org/10.1023/A:1009715923555 
28. Hsu CW, Chang CC, Lin CJ. A practical guide to support vector classification.

29. Ben-Hur A, Ong CS, Sonnenburg S, Schölkopf B, Rätsch G. Support Vector Machines and Kernels for Computational Biology. PLoS Comput Biol. 2008 Oct; 4(10):1-10. https://doi.org/10.1371/journal. pcbi.1000173

30. Wong TT. Performance evaluation of classification algorithms by k-fold and leave-one-out cross validation. Pattern Recognit. 2013 Sep;48(9):2839-46. https://doi.org/10.1016/j.patcog.2015.03.009

31. De Stefano NJ, Filippi M. MR spectroscopy in multiple sclerosis. J Neurol Sci. 2007 Apr;17:31-35. https://doi.org/10.1111/j.15526569.2007.00134.x

32. García-GómezJM, Luts J, Julià-Sapé M, Krooshof P, Tortajada S, Robledo $\mathrm{JV}$, et al. Multiproject-multicenter evaluation of automatic brain tumor classification by magnetic resonance spectroscopy. MAGMA. 2009 Feb;22(1):5-18. https://doi.org/10.1007/s10334-008-0146-y

33. Tsolaki E, Svolos P, Kousi E, Kapsalaki E, Fountas K, Theodorou K, et al. Automated differentiation of glioblastomas from intracranial metastases using 3T MR spectroscopic and perfusion data. Int J Comput Assist Radiol Surg. 2013 Sep; 8(5):751-61. https://doi. org/10.1007/s11548-012-0808-0

34. Georgiadis P, Kostopoulos S, Cavouras D, Glotsos D, Kalatzis I, Sifaki $\mathrm{K}$, et al. Quantitative combination of volumetric MR imaging and MR spectroscopy data for the discrimination of meningiomas from metastatic brain tumors by means of pattern recognition. Magn Reson Imaging. 2011 May;29(4):525-35. https://doi.org/10.1016/j. mri.2010.11.006

35. Luts J, Heerschap A, Suykens JA, Van Huffel S. A combined MRI and MRSI based multiclass system for brain tumour recognition using LS-SVMs with class probabilities and feature selection. Artif Intell Med. 2007 Jun;40(2):87-102. https://doi.org/10.1016/j. artmed.2007.02.002

36. Feinstein A, Freeman J, Lo AC. Treatment of progressive multiple sclerosis: what works, what does not, and what is needed. Lancet Neurol. 2015 Feb;14(2):194-207. https://doi.org/10.1016/S14744422(14)70231-5 